\title{
Imaginário social sobre o SUS e vulnerabilidade de homens ao acesso a diagnóstico e tratamento de infecções sexualmente transmissíveis
}

\author{
The social imaginary about SUS and the vulnerability of men to access to \\ diagnosis and treatment of sexually transmitted infections

\section{El imaginario social sobre el SUS y la vulnerabilidad de los hombres en el acceso al diagnóstico y tratamiento de infecciones sexualmente transmisibles}

\author{
Neide Emy Kurokawa e Silva | neks@iesc.ufrj.br \\ Universidade Federal do Rio de Janeiro, Instituto de Estudos em Saúde Coletiva. Rio de Janeiro, RJ, Brasill.
}

\section{Resumo}

A partir do reconhecimento da importância das dimensões socioculturais e simbólicas no acesso dos homens ao diagnóstico e tratamento de infecções sexualmente transmissíveis (IST), discute-se se e como suas concepções sobre o SUS podem vulnerabilizá-los na busca de cuidado, diante de suspeita de IST, tendo como referência a noção de imaginário social. Foram realizados quatro grupos focais, a partir dos quais foram apreendidos e analisados os discursos dos homens sobre possíveis locais em que procurariam ajuda, em caso de suspeita de IST. A imagem negativa que fazem do sistema público de saúde é construída a partir de referências que extrapolam suas vivências diretas, na qual a mídia parece ter um papel preponderante. À crítica do SUS, os planos de saúde privados emergem como solução redentora. A despeito da importância da participação social, essa noção não se fez presente nos discursos, levando à necessidade de melhor compreender e fomentar tal iniciativa.

Palavras-chave: Acesso; Infecções sexualmente transmissíveis; Memória coletiva; Imaginário social; Sistema Único de Saúde.

\begin{abstract}
It is postulated the difficulty of men in the access to diagnosis and treatment of sexually transmitted infections (STI). Considering that access is also molded by sociocultural and symbolic dimensions, it is discussed if and how men's apprehensions of SUS (the Unified Health System), can make them vulnerable when seeking for care, facing a suspicion of STI, holding as reference the notion of social imaginary. From the execution of four focal groups, it was analyzed the speeches of men about places where they would look for help, in case of suspicion of STI. The negative image that they have about the public health system is built from references that extrapolate their direct experience, in which the media seems to have a preponderant role. To the criticism of SUS private health insurance emerge with redeeming solution. Despite the importance of social participation, this notion was not present in those speeches, leading to the necessity of better comprehending and fomenting such initiative
\end{abstract}

Keywords: Access; Sexually transmitted infections; Collective memory; Social imaginary; Unified Health System. 


\section{Resumen}

A partir del reconocimiento de la importancia de las dimensiones socio-culturales y simbólicas en el acceso de los hombres al diagnóstico y tratamiento de infecciones sexualmente transmisibles (IST), se discute si y cómo sus concepciones sobre el SUS lo pueden vulnerabilizar en la búsqueda de cuidado, frente a la sospecha de IST, teniendo como referencia la noción de imaginario social. Fueron realizados cuatro grupos focales, a partir de los cuales fueron aprehendidos y analizados los discursos de los hombres sobre posibles lugares en que buscarían ayuda, en caso de sospecha de IST. La imagen negativa que tienen del sistema público de salud es construida a partir de referencias que extrapolan sus vivencias directas, en la cual los medios de comunicación parecen tener un papel preponderante. A la crítica del SUS, los planes de salud privados emergen como solución redentora. A pesar de la importancia de la participación social, esa noción no está presente en los discursos, llevando a la necesidad de comprender mejor y fomentar tal iniciativa.

Palabras clave: Acceso; Infecciones sexualmente transmisibles; Memoria colectiva; Imaginario social; Sistema Único de Salud.

Declaração de conflito de interesses: A autora declara que não há quaisquer conflitos de interesse.

Fontes de financiamento: CNPQ Universal 14/2012. Proc.476020/2012-3.

Considerações éticas: O projeto foi aprovado pelo Comitê de Ética em Pesquisa do Instituto de Estudos em Saúde Coletiva (IESC/UFRJ) - CAAE: 01545512.5.0000.5286/2013.

Histórico do artigo: Submetido: 15.out.2015 | Aceito: 25.jan.2016 | Publicado: 31.mar.2016

Apresentação anterior: $O$ artigo teve por base o resumo de trabalho apresentado no $11^{\circ}$ Congresso Brasileiro de Saúde Coletiva - 2015, intitulado: "Graças a Deus eu tenho plano de saúde": imaginário de homens sobre o SUS e a vulnerabilidade no acesso ao diagnóstico de DST". Disponível em: http://www.saudecoletiva.org.br/anais/index_int.php?id_trabalho=2632\&ano=\&ev=\#menuanais

Licença: CC BY-NC atribuição não comercial. Com essa licença é permitido acessar, baixar (download), copiar, imprimir, compartilhar, reutilizar e distribuir os artigos, desde que para uso não comercial e com a citação da fonte, conferindo os devidos créditos de autoria e menção à Reciis. Nesses casos, nenhuma permissão é necessária por parte dos autores ou dos editores 


\section{Introdução}

Sabe-se que hoje em dia a maior parte das infecções sexualmente transmissíveis (IST) são curáveis ou tratáveis; no entanto, o quadro sanitário ainda é preocupante: ao dia, cerca de um milhão de pessoas no mundo adquirem alguma dessas doenças ${ }^{1}$.

Mesmo considerando as limitações do sistema de notificação, como a subnotificação de casos e inclusão de apenas algumas IST, restringindo a determinação da magnitude do problema, a Organização das Nações Unidas estimou que, no Brasil, o número de infecções de transmissão sexual na população sexualmente ativa, a cada ano, corresponderia a 12 milhões de casos $^{2}$.

O próprio Ministério da Saúde reconhece que, a despeito da indicação do diagnóstico e tratamento sindrômico, a fim de otimizar a atenção, há uma ênfase no diagnóstico etiológico e o manejo sindrômico é pouco conhecido pelos profissionais de saúde. Além disso, as diretrizes para diagnóstico e tratamento precoces, incluindo as parcerias sexuais, são pouco conhecidas ou implementadas pelo sistema de saúde. Não existe disponibilidade contínua de medicamentos padronizados para portadores de IST, bem como de preservativos ${ }^{3}$.

Nesse contexto, comparativamente às mulheres, pode-se dizer que os homens têm menos chances de acessarem os serviços de saúde; elas, ao menos por ocasião do acompanhamento do pré-natal, realizam exames que cobrem as principais IST. A esse panorama somam-se as dificuldades para marcar uma consulta em serviço de saúde, além da restrita oferta de horários e dias de atendimento, compatíveis com as necessidades dos homens. A indefinição quanto às responsabilidades da atenção primária no acolhimento das demandas de IST, que mormente são referidas a serviços especializados, independentemente da complexidade do caso, também é mencionada como uma barreira à atenção à saúde dos homens com suspeita de IST ${ }^{3-5}$.

Ao lado das citadas barreiras programáticas no acesso dos homens a diagnóstico e tratamento de IST, é importante considerar o papel das dimensões socioculturais que modelam tanto os entendimentos sobre a saúde e a doença, quanto as escolhas e trajetórias percorridas por eles em busca de cuidado. Concepções sobre masculinidade e saúde, por exemplo, podem dificultar a iniciativa de alguns homens de buscarem algum serviço ou profissional de saúde, a partir da ideia, ainda que controversa, de que homem não gosta ou não valoriza o cuidado com sua saúde . $^{6}$

É relevante demarcar que cada uma das dimensões, sejam programáticas, sociais ou culturais, não opera isoladamente, posto que, recorrendo ao exemplo citado, não se pode desconsiderar que os "postos de saúde" foram historicamente configurados para a atenção materno-infantil, perdurando até hoje algumas heranças dessa ênfase no imaginário da população ou mesmo de profissionais de saúde.

Buscando compreender o acesso ao cuidado em saúde para além do binômio demanda-oferta, e analisando-o a partir das diferentes dimensões - sociais, programáticas e individuais - as quais, em interação, podem facilitar ou dificultar a sua realização, foi desenvolvido estudo que teve como referência o quadro da vulnerabilidade ${ }^{7-8}$, focalizando o acesso dos homens ao diagnóstico e tratamento de IST (excluindo-se HIV e Aids). Tal quadro permitiu examinar integradamente as diferentes dimensões - individuais, sociais, culturais, programáticas - que podem dificultar o referido acesso e como são articuladas, apreendidas e significadas9 .

Um dos achados do referido estudo apontou para uma maciça desqualificação dos serviços públicos de saúde, por parte dos informantes, levando-nos a indagar sobre possíveis repercussões desse tipo de avaliação no âmbito do acesso ao cuidado com a saúde.

O presente artigo toma como ponto de partida as dimensões simbólicas que podem servir de obstáculo à busca de cuidado com a saúde, discutindo mais especificamente se e como as apreensões dos homens em relação ao SUS podem vulnerabilizá-los no acesso aos serviços de saúde, diante de suspeita de doença sexualmente transmissível, tomando como fio condutor a noção de imaginário social. 


\section{Metodologia}

O estudo foi realizado entre 2013 e 2014, no Rio de Janeiro e em São Paulo, em campos clínicos (serviços especializados em IST) e campos não clínicos (envolvendo trabalhadores de uma instituição pública federal de ensino e trabalhadores de uma empresa interestadual de ônibus). No primeiro caso foram realizadas entrevistas individuais em profundidade, com roteiro semiestruturado, a 18 homens com diagnóstico de IST, em seguimento no serviço de saúde especializado. Nos campos não clínicos foram feitos quatro grupos focais, sendo três no Rio de Janeiro (G1, G2, G3) e um em São Paulo (G4). Participaram de 10 a 17 homens em cada um deles. Em todos os campos não clínicos, a principal ocupação foi relacionada a atividades de manutenção e reparação, seguida de um pequeno contingente envolvido com atividades administrativas. Nos campos não clínicos do Rio de Janeiro a idade dos participantes variou entre 33 e 68 anos; no de São Paulo a faixa etária oscilou entre 31 e 57 anos. A maior parte dos participantes era casada e a escolaridade nos campos do Rio de Janeiro era majoritariamente de ensino fundamental incompleto, ao passo que no campo São Paulo, a maior parte possuía ensino médio completo.

Tabela 1- Perfil dos participantes dos grupos focais

\begin{tabular}{|c|c|c|c|c|c|c|c|}
\hline \multirow{2}{*}{$\begin{array}{l}\text { Grupos } \\
\text { focais }\end{array}$} & \multirow{2}{*}{$\begin{array}{l}\text { Data } \\
\text { realização }\end{array}$} & \multirow{2}{*}{$\begin{array}{l}\text { Número } \\
\text { participantes }\end{array}$} & \multirow[t]{2}{*}{ Faixa etária } & \multicolumn{2}{|c|}{ Estado civil } & \multicolumn{2}{|c|}{ Escolaridade } \\
\hline & & & & solteiros & casados & ens. fund. & ens. médio \\
\hline G1 & 04.09 .2013 & 11 & $47-66$ anos & 0 & 11 & 07 & 04 \\
\hline $\mathrm{G} 2$ & 11.09 .2014 & 10 & $46-68$ anos & 02 & 08 & 09 & 01 \\
\hline G3 & 24.11 .2014 & 17 & 33-57 anos & 04 & 13 & 08 & 07 \\
\hline G4 & 28.11 .2014 & 11 & 31-57 anos & 0 & 11 & 08 & 03 \\
\hline
\end{tabular}

Fonte: Elaborada pela autora.

No campo clínico, o acesso dos homens foi apreendido a partir dos itinerários terapêuticos ${ }^{10}$ percorridos por eles, desde a suspeita de alguma anormalidade até a chegada ao serviço especializado. Nos grupos focais ${ }^{11}$, entre outros aspectos, exploraram-se situações hipotéticas sobre iniciativas e reações pessoais diante de sinal ou sintoma de IST, como corrimento, verruga, dificuldade para urinar.

A investigação em pauta foi motivada pelo estranhamento em relação às espontâneas e recorrentes expressões avaliativas e comparativas entre os serviços oferecidos por órgãos públicos e aqueles ofertados por convênios e consultórios médicos particulares. Nesse sentido, o substrato para os objetivos do presente artigo foi proveniente das falas dos depoentes dos grupos focais, cujo propósito foi perscrutar as trajetórias antevistas pelos homens, diante de suspeita de IST. Embora os serviços públicos de saúde tenham sido identificados pelos informantes simplesmente como "serviço público", "UPA" (Unidade de Pronto Atendimento), "AMA" (Assistência Médica Ambulatorial), "hospital público" ou "posto de saúde" e apenas um informante tenha mencionado explicitamente o SUS, os comentários aqui tecidos recorrerão a essa sigla para referir-se aos serviços que compõem o sistema público de saúde. Com base na análise de discurso ${ }^{12}$, o material teve como referência os argumentos utilizados para a busca de cada uma dessas modalidades de atenção à saúde. 


\section{Resultados}

\section{Trajetórias vividas e antevistas: memória coletiva sobre o SUS}

Frente ao número médio de doze participantes por grupo, chamou-nos a atenção a proporção de experiências com IST, envolvendo diretamente os participantes ou sua rede familiar e de amizade: de três a seis casos, por grupo, a maior parte envolvendo gonorreia ou sífilis. Nos relatos, sobressaíram depoimentos sobre o desconforto dos sintomas de IST, temores em relação à aids, constrangimentos e vergonha de procurar ajuda, embaraços envolvendo companheiras, além de menção à ocorrência dessas doenças como algo natural entre homens, especialmente os jovens. Também foram citadas cenas de discriminação por parte de amigos e familiares, embora não percebida como tal. Essas vivas experiências, em diferentes períodos da vida, em serviços públicos e privados, não incluíram avaliações, nem sobre o acesso nem sobre a qualidade do atendimento propriamente dito, à exceção de um tratamento malsucedido, prescrito em farmácia.

Entretanto, quando instigados a comentar, no plano hipotético, sobre o quê fariam caso se deparassem com um sinal ou sintoma de IST, a dimensão avaliativa preponderou, sendo marcante o descrédito dos participantes em relação aos serviços públicos de saúde.

Para responder à situação fictícia apresentada, sobre lugares que buscariam diante de suspeita de IST, os homens não se reportaram às trajetórias experienciadas e relatadas no cuidado com essas doenças, sendo apontada a busca de algum médico especialista (urologista ou dermatologista), indicado ou referenciado por um médico clínico, ou então por algum serviço de saúde. No campo do Rio de Janeiro o serviço nominalmente expresso foi a Unidade de Pronto Atendimento (UPA) e em São Paulo foram lembrados os serviços especializados de IST, como possíveis locais de atendimento, no caso de suspeita desses agravos. Também foram feitas referências esparsas à busca em farmácias, internet ou de algum amigo de confiança.

À conjectura de busca de cuidado em serviços públicos de saúde, os homens teceram comentários dramaticamente desabonadores, mas em geral sem amparo em exemplos concretos. A avaliação pareceu resvalar no resgate de um conjunto de impressões que extrapolavam experiências imediatas, englobando representações temporais e geográficas inespecíficas.

As UPAS, por exemplo, foram significadas como locais com pouca resolutividade, de atenção meramente paliativa:

Eles atendem você lá, fazem uma fichinha. Te atende na hora, te dá alguma medicação. E manda você pra um hospital pra procurar um médico que possa tratar daquela doença”. (GF1). ou: Geralmente eles dão uma injeção e...ó, procura outro médico (...) O que o paciente espera dele é que ele não dê essa injeção, mas que dê continuidade no tratamento até essa doença já estar curada.(GF2).

Mesmo buscando indicar alguma utilidade para a sua existência, reforça-se a falta de resolutividade desses serviços: “O UPA não vai te resolver o problema, mas dá uma dica, ele já te informa onde tem que ir". (GF1)

Embora tal impressão pudesse estar fundamentada em experiências concretas, ela não foi situada, circunscrevendo-se geralmente a comentários genéricos: não se sabe precisamente quem passou pela situação, quando, nem onde. As críticas dirigidas aos serviços públicos de saúde foram preponderantemente derivadas da mídia, especialmente a televisiva, que, por exemplo, exibiu a "saga das mulheres com câncer de mama, que dependiam do sistema público e não tinham condições de pagar um plano de saúde" (GF4) ou que refere:“a pessoa morrendo lá. Sem médico. Sem hospital que atenda. Deitado lá no chão lá”.(GF1).

A decodificação e a explicação para situações como essa resultam na imputação da responsabilidade não assumida ou, mais claramente, da culpa do governo, expresso em falas como:

Não falta UPP, mas falta remédio; o governo tá muito preocupado com estádio, Copa do Mundo. O dinheiro que o governo investiu nos estádios dava pra construir vários hospitais. Eu vi na reportagem 
(GF1); A área da saúde tá muito precária. Então, o próprio governo não dá condições pra sociedade ser bem atendida nessa área. (GF2); O interesse público não tem interesse nenhum com a gente. (GF3); Porque eu ia perder o pé e nem me internar eles queriam. Por causa de quê? Governo não dá verba pros hospitais. Os hospitais hoje não têm médico. Os hospitais hoje tão... Vendendo os próprios hospitais. É culpa do governo. Governo que destrói a saúde. Não é o médico, não é o funcionário, não é o trabalhador, é o próprio governo. (G3).

A culpabilização do governo pelos problemas da saúde, fomentada pela própria mídia, já foi apontada por estudo que analisou um jornal de grande circulação em São Paulo, indicando como esse veículo, a partir de estratégias discursivas específicas, fomenta a construção de uma imagem de incompetência do governo e de indeterminação da inserção do usuário no sistema de saúde ${ }^{13}$.

Outra investigação também denunciou a pouca reflexividade que a mídia propicia, alardeando mazelas sobre o SUS:

As principais imagens e informações publicamente divulgadas pela mídia sobre o SUS são mais comumente associadas às mazelas e dificuldades do setor, quase sempre a partir de uma suposta ineficiência do Estado, incompetência das autoridades ou dos profissionais da área, levando à construção de uma ordem simbólica pouco reflexiva sobre o campo da política de saúde representada pelo SUS. ${ }^{14}$.

A aparente dissociação entre trajetórias vividas e trajetórias antevistas pode sugerir descontinuidade entre a memória acerca dessas referências e a possibilidade de elas guiarem a busca do serviço de saúde, no futuro. Como compreender a ausência ou escassez de relatos específicos sobre experiências mal sucedidas no SUS e a peremptória desqualificação e descrédito no serviço público?

Embora o SUS já tenha completado mais de 20 anos, apenas um participante de um dos grupos focais, como já mencionado, evocou essa sigla, sugerindo o desconhecimento ou mesmo a sua identidade incipiente junto à população, não obstante iniciativas como as de associá-lo ao "melhor plano de saúde"15.

A despeito da radical mudança carreada pelo SUS, as dimensões dessas mudanças parecem não repercutir na população. Em estudo ${ }^{16}$ que investigou memória social e representações sobre o SUS, os informantes não conseguiram precisar quando esse sistema foi implantado, o que, na conclusão dos autores, pode indicar o não reconhecimento das mudanças operadas, em relação aos modelos anteriores. Na mesma direção, pesquisa encomendada pelo Conass indicou que 55,3\% dos entrevistados não sabiam o significado da sigla SUS ${ }^{17}$.

$\mathrm{O}$ recurso à noção de memória coletiva ${ }^{18}$ parece apropriado para o entendimento sobre a imagem que se constrói sobre o SUS, considerando que o ordenamento do mundo não é individual, indiferenciando-o dos sistemas de saúde que o antecederam. E o caráter recorrente e repetitivo, validado pelo grupo, ou mesmo fora dele, constitui-se como a principal manifestação do que seja uma memória coletiva ${ }^{18}$.

A memória é uma reconstrução psíquica e intelectual que acarreta de fato uma representação seletiva do passado, um passado que nunca é aquele do indivíduo somente, mas de um indivíduo inserido num contexto familiar, social, nacional. Portanto toda memória é, por definição, 'coletiva'. ${ }^{18 .}$

Nesse sentido, compreende-se que a memória e a imagem do serviço público de saúde não são instruídas apenas por acontecimentos testemunhados pessoalmente, mas também por aqueles vividos pelo grupo ou pela coletividade. Assim, são produto do reconhecimento dessas experiências mais amplas, que transcendem o tempo e o espaço imediato dos informantes.

A inflexão decorrente da transformação do modelo assistencial não fez parte das falas dos informantes e mudanças como a ampliação do cardápio de oferta de atendimento na atenção primária - para além da saúde materno-infantil, como exemplo mais visível da mudança - sequer foram citadas.

Não se pode ignorar situações concretas de dificuldades no acesso, falta de recursos, gestão ineficiente, entre outros problemas, mas há que se reconhecer a existência de contextos que favorecem a legitimação de determinadas configurações da memória coletiva, que reforçam um claro processo de desqualificação do SUS. 
A mídia, mais que um importante espaço de disseminação de informações, é coprodutora de sentidos no cotidiano das pessoas ${ }^{19} \mathrm{e}$, como já indicado, pode ser uma das forças que tem atuado no sentido de achacar o sistema, atribuindo e radicalizando posições ou de vítimas ou de algozes, em referência à população e ao governo, respectivamente.

Em pesquisa iconográfica sobre o SUS, Narvai ${ }^{20}$ aponta que, além de não seguirem um modelo padronizado, é ausente ou pouco visível a sua logomarca em equipamentos de saúde financiados pelo sistema, incluindo postos de saúde, hospitais, ambulâncias e outros. Mais precisamente, para além da pouca visibilidade, o autor interpreta tal lapso como "ocultamento do SUS".

Não há como negar a existência de contextos que favorecem a reprodução e cristalização de uma imagem negativa sobre os serviços públicos de saúde, capitaneados por interesses econômicos e/ou políticos e fomentados ativamente pela mídia.

A mídia certamente representa parte deles, assumindo, na sociedade contemporânea, um importante papel na construção e disseminação de informações, acontecimentos e descobertas, influenciando as formas como as pessoas significam e se posicionam diante dos fenômenos sociais. A produção midiática envolve intrincado jogo de interesses e acordos institucionais, não podendo se desconsiderar o caráter ideológico de suas mensagens ${ }^{21}$ na construção da memória coletiva que modela os sentidos atribuídos ao SUS. Nessa moldura, ao propalado malogro do sistema público de saúde, os planos de saúde emergem como solução redentora.

\section{"Graças a Deus, eu tenho plano de saúde"}

O atendimento dependente do SUS, diante da ocorrência hipotética de algum sinal sugestivo de IST, é comparado pelos depoentes a um jogo de azar, cuja realização é incerta e, quando ocorre, pode não ser resolutivo: "A gente vai lá, tentar a sorte!" (G3) ou é fácil diagnosticar a doença, mas fazer o tratamento você já fica com aquela dificuldade porque a área da saúde tá muito precária.” (G3). Além dessa percepção, a utilização do serviço público de saúde, para aqueles que não dispõem de uma outra alternativa, é apontada como uma espécie de condenação, como a opção dos que não têm opção.

O ideal de atenção foi expresso como a posse de um plano de saúde, que corresponderia a um objeto do desejo, não disponível a todos os indivíduos. Vale pontuar que os funcionários da empresa de transporte, onde foram realizados dois grupos focais, podem optar pela adesão a um plano de saúde, cuja contribuição é descontada do salário. Nem todos fazem essa adesão, segundo os depoentes, por "questões financeiras". Já os participantes dos grupos focais do serviço público não contavam com esse benefício, e alguns deles, por iniciativa pessoal, haviam contratado planos de saúde.

A possibilidade de contar com um plano de saúde emerge como saída para esse jogo de azar ou condenação, e as comparações entre ambos foram sempre desfavoráveis ao serviço público; a depreciação do serviço público parece ser proporcional à imagem positiva ou salvadora do plano de saúde, como exemplifica o depoimento de um dos participantes da pesquisa:

Movido pelas campanhas de prevenção ao câncer de próstata e ao incentivo à realização do exame de toque como forma privilegiada de diagnóstico precoce, descreve a resistência do médico de um posto de saúde em realizar referido exame, mesmo diante do seu pedido. Sua crítica ao médico do serviço público é acompanhada do enaltecimento da possível conduta em um serviço conveniado de saúde: "É muito comum no serviço público essa história do médico, às vezes, se recusar de fazer o toque na pessoa... é um crime! Se eu comentasse isso num plano de saúde, com certeza chamariam a atenção do médico porque ele não pode se recusar a isso". (G3). 
Destaca-se que, nos grupos focais, a peremptoriedade de comentários como o acima transcrito, pregando a certeza de um bom atendimento por parte do plano de saúde, resistiu vigorosamente às manifestações que poderiam colocar em dúvida o status redentor dos planos de saúde:

Mesmo no convênio. Porque, antigamente, você marcava um exame dentro de uma semana. Hoje, de um a dois meses num convênio pra você marcar um exame. Um exame básico. Não é nem profundo. Um exame básico. Mas no convênio não tem vaga. Só tal dia. No mês que vem. Esse mês não tem vaga. (GF3).

Essa fala foi rebatida imediatamente com o comentário: "imagine se fosse no SUS!" (GF3), sugerindo uma incontestável inferioridade qualitativa do atendimento do SUS em relação aos planos de saúde. Além desse adendo, visando manter o enaltecimento do plano de saúde, outros conjuntos argumentativos buscaram sustentar sua visão, tal como: "Antigamente, quem tinha um plano de saúde era status, né? Pô! O cara tem plano de saúde. Você chegava pra marcar uma consulta 09:0oh da manhã, no mais tardar você era atendido 09:15 da manhã pelo médico. Hoje...”.(GF3).

E o mesmo depoente complementa: "Pode ser o plano que a gente tem... O mais lá em embaixo, o mais... Que seja! Você marca uma consulta, você chega lá, ele tá pior que o antigo INPS." (GF3). (grifo nosso).

Simultaneamente à denúncia da falha, emergiu a justificativa de que a deficiência relatada residia no tipo de oferta de plano de saúde proporcionado pela empresa - "o mais lá embaixo". O recurso à imagem negativa do extinto Instituto Nacional de Previdência Social poderia sugerir a evocação de que hoje o SUS seria melhor, mas o conteúdo do comentário não permitiu tal interpretação.

A adesão aos planos de saúde transcende possíveis critérios objetivos como a disponibilidade de recursos financeiros do cidadão para tal ou mesmo a possibilidade de desfrutar da suposta qualidade ou acessibilidade na atenção à saúde. Envolve aspectos híbridos, como a segurança, conforme apontado por Farias $^{22}$, que investigou a adesão a planos de saúde, por indivíduos de camadas populares. O estudo mostrou que a insatisfação com os serviços públicos de saúde não determinam, por si, a contratação de planos de saúde, só se efetivando quando a necessidade de segurança em relação à saúde ocupa posição de destaque entre as prioridades dos indivíduos, expressando a complexidade das interações materiais e simbólicas entre os sujeitos e o sistema de saúde.

É interessante notar que a definição de qualidade, nos grupos, foi se configurando a partir de aspectos que a negam, mormente atribuída ao serviço público. De qualquer modo, a qualidade no atendimento pareceu associada à agilidade na marcação de exames e consultas, resolutividade, acolhimento e respeito por parte dos profissionais, em especial, dos médicos, como indicam os depoimentos:

As pessoas tão morrendo de pressão alta. Chega lá, vai lá só botar aparelho. Enche o saco de remédio e vai pra casa. Fica se matando aos poucos. (G1). Eles passam uma receitazinha prá senhora, a senhora compra esse remédio e acabou. A senhora não é bem recebida num hospital desse. A culpa de tudo isso é de quem? Do governo. Não tem como administrar um hospital se não tem verba. Se não tem verba, não tem médico. A população sofre com isso. Vai ficar horas e horas na fila e não vai ser atendida porque não tem médico. E não pode comprar remédio sem receita. O cara tem que ter uma coisa particular". (G3).

Se o retrato da situação da saúde no país é unânime no grupo, também se nota a fragilidade dos argumentos levantados e das soluções apresentadas:

Eu sou contra posto de saúde no Brasil. Eu sou contra. Eu, pra mim... Acabava com posto de saúde. Porque a maioria das pessoas não têm qualificação pra trabalhar lá, só tá empurrando energia pra dificultar aquilo lá... Porque posto de saúde, eles não têm qualificação, o governo não investe nessa área, fica só dando remedinho..." (G5). "Eu chego lá, quando tem funcionário público acima de 60 anos, eu não... Não passo naquela pessoa pra fazer uma ficha... Então, aposentou? Sai fora. Porque dá a vaga pra quem quer trabalhar.... Então, vai tomar cafezinho. (G1).

O destaque da penetração das informações da mídia na construção do imaginário sobre o sistema público de saúde poderia dar margem à interpretação de que a população seria apenas um receptor passivo do conteúdo 
divulgado pela TV, rádio, jornais. Entretanto, postula-se que a apreensão dos significados negativos sobre o sistema de saúde e a sua reprodução faz parte de um processo mais complexo, no qual esses significados não são construídos apenas a partir de um retrato do presente, mas são informados pela memória coletiva, os quais, juntos, delineiam expectativas quanto ao futuro e às possibilidades ou não de mudanças.

A partir dos discursos dos participantes dos grupos focais, foi possível apreender que o projeto privilegiado de mudança ou de ideal de atenção à saúde corresponde à posse de um plano de saúde, reiterando-se a premissa de que a desqualificação do SUS seria proporcional ao enaltecimento dos planos de saúde.

O encadeamento discursivo de um dos depoentes expressa essa exaltação, mesmo a despeito de um atendimento resolutivo no serviço de saúde:

Um belo dia, quando eu acordei que eu fui ao banheiro, urinei sangue. Naquele dia mesmo eu saí do trabalho, já fui pro médico. Naquela época não existia plano de saúde. Eu, graças a Deus, eu tenho plano de saúde. Né? Então... Tratamento, eu não dependo do hospital público. Então, naquela época, eu não tinha plano de saúde... Quando eu falei que urinava sangue, me encaminharam na mesma hora. Não me deixaram pro dia seguinte, nem nada. Na mesma hora me encaminharam. (G3). (grifos nossos).

O relato poderia referir-se a uma experiência bem-sucedida, de acolhimento imediato no serviço público de saúde, entretanto, a ênfase recaiu no que seria a opção mais adequada (e almejada), inexistente na época: o plano de saúde.

A imagem dos serviços públicos de saúde, hoje correspondentes ao SUS, tem merecido perspectivas de análise dicotômicas, em torno do "SUS formal" e do "SUS real", exprimindo contrastes entre os ideais proclamados por ocasião de suas concepção e institucionalização e a dificuldade no acesso e precariedade da atenção à saúde no país. Esse campo simbólico e a dinâmica social que, no caso, engendra e sustenta representações polares, bem como a idealização salvadora dos planos de saúde, podem ser compreendidas a partir da noção de imaginário social

Se a memória coletiva proporciona um modo peculiar de atualizar as apreensões acerca do passado, a noção de imaginário social permite compreender o vigor das construções em torno do SUS e dos planos de saúde e os projetos produzidos pela mesma.

Ainda que merecendo diversas abordagens, a noção de imaginário social busca desconstruir a visão cindida entre um suposto real e o imaginário, que toma esse último como fantasia, juízo subjetivo ou falsa de consciência de coisas reais. Também é importante distinguir o imaginário da imaginação, não obstante sua proximidade etimológica. A imaginação associa-se a uma representação individual, mais associada a um processo emocional e cognitivo. O imaginário, por sua vez, "constitui uma "gramática”, um esquema referencial para interpretar a realidade socialmente legitimada, construída intersubjetivamente e historicamente determinada. A imaginação é representativa, o imaginário, interpretativo”23.

Nesse universo é também importante destacar a ideia de imagem, não como algo que condiciona o imaginário mas, ao contrário, como produto do imaginário ${ }^{24}$, salientando a pertinência da preocupação de Narvai ${ }^{20}$ com a ausência (ou ocultação) da imagem do SUS nos equipamentos públicos de saúde.

Se, de um lado, o imaginário social pode lançar luzes sobre a compreensão do enaltecimento dos planos de saúde, em detrimento dos serviços públicos de saúde, por outro, poderia sugerir a presentificação e a cristalização das imagens que produzem.

A essa leitura fatalista, alguns dos autores que tratam do imaginário social avançam na sua definição, enfatizando, para além de permitir um modo de percepção e explicação dos contextos sociais e históricos, as possibilidades de transformação desses contextos.

Considera-se que na conformação de um imaginário social estarão sempre presentes contradições e oposições no seio das experiências socialmente compartilhadas, levando a situações em que alguns imaginários se "impõem" sobre outros. Sobre esta leitura, Baeza ${ }^{25}$ fala em imaginários dominantes e imaginários dominados, expressando as disputas pela imposição de determinadas visões de mundo. 
A diversidade de perspectivas em disputa abriria caminho para a possibilidade de redefinição dos imaginários sociais dominantes.

Nesse sentido, cabe acentuar a distinção proposta por Castoriadis ${ }^{26}$, entre o imaginário que se reduz à reprodução de imagens e aquele que põe em relevo a sua potência criativa, inovadora e transformadora no âmbito social e histórico, o qual denomina imaginário radical.

No contexto do problema apresentado, qual seria a fonte privilegiada de exercício do imaginário radical, senão a própria participação popular, um dos caros princípios organizativos do SUS?

Os discursos dos participantes da pesquisa não vislumbraram o agenciamento da população como estratégia para mudança do cenário apresentado, reduzindo-a basicamente à aquisição de um plano de saúde.

Sobre possíveis canais para reclamação, os participantes ou não souberam responder ou sugeriram referências como a polícia, o juiz ou a televisão, essa última considerada pelos grupos como um meio efetivo para mobilizar as autoridades e, quiçá, a população: "Olha, pra falar a verdade, hoje no Brasil não tem onde reclamar. A única coisa que tem a reclamar hoje em dia é se você procurar os canais de televisão. E achar alguém que te dá uma liberdade de você reclamar". (GF3).

A mídia parece ser ponto de partida e de chegada na compreensão sobre a construção do imaginário social envolvendo os serviços públicos e os planos de saúde, na medida em que se constitui como importante agente de disseminação de imagens negativas sobre o primeiro e como meio privilegiado de referência a partir da qual a opinião pública pode ressoar junto ao Estado.

\section{Considerações finais}

A partir do percurso empreendido para fazer face aos objetivos do artigo, é possível dizer que o acesso de homens a diagnóstico e tratamento de IST pode ser vulnerabilizado pelos sentidos e significados atribuídos aos serviços públicos de saúde e pela apreensão redentora que se faz dos planos de saúde.

O conhecimento do modo de construção da memória coletiva e do imaginário social e os possíveis interesses e disputas presentes possibilitaram, por sua vez, compreender como essas apreensões simbólicas podem vulnerabilizar referido acesso. Por um lado, a reprodução e cristalização do imaginário negativo sobre o SUS pode tanto desestimular a busca de cuidado quanto não validar o atendimento prestado. Por outro, ao não se vislumbrar o reconhecimento e a transformação daquilo que não funciona, a única saída passa a ser a posse de um plano de saúde, o qual, por sua vez, não necessariamente irá atender às demandas dos homens, no cuidado às IST.

Não obstante o possível pessimismo no quadro apresentado, insiste-se na abertura sugerida pelas próprias referências apresentadas, no qual o imaginário social reprodutor e cristalizador das imagens acerca do SUS possa ceder espaço para um imaginário radical, crítico, agenciador e transformador de realidades. Para tanto, a despeito das iniciativas já existentes, reforça-se a relevância do investimento em ações visando ao fomento da cidadania e da participação popular. 


\section{Referências}

1. World Health Organization. Global strategy for the prevention and control of sexually transmitted infections: 2006 - 2015 : breaking the chain of transmission; 2007.

2. WHO. Sexually transmitted infections prevalence study methodology: guidelines for the implementation of STI prevalence surveys. World Health Organization; 1999.

3. Brasil. Ministério da Saúde. Secretaria de Vigilância em Saúde. Programa Nacional de IST/Aids. Manual de controle das infecções sexualmente transmissíveis. 4a ed. Brasília: Ministério da Saúde; 2006. Série A. Normas e Manuais Técnicos.

4. Araujo MAL, Leite MA, Silva DMA, Silva RM, Gonçalves MLC. Análise da qualidade dos registros nos prontuários de gestantes com exame de VDRL reagente. Rev APS [Internet]. 2008; 11(1):4-9. [citado 11 out 2015]. Disponível em: http://www.ufjf.br/nates/files/2009/12/004-009.pdf

5. Araújo MAL, Leitão GCM. Acesso à consulta a portadores de infecções sexualmente transmissíveis: experiências de homens em uma unidade de saúde de Fortaleza, Ceará, Brasil. Cad. Saúde Pública [Internet]; 2005 21(2):396-403. [citado 11 out 2015]. Disponível em: http://www.scielo.br/pdf/csp/ v21n2/06.pdf

6. Figueiredo WS. Assistência à saúde dos homens: um desafio para os serviços de atenção primária. Ciênc. saúde coletiva [Internet]; 2005 [citado 11 out 2015]; 10(1):105-109.Disponível em: http://www. scielo.br/pdf/csc/v10n1/a11v10n1

7. Ayres JRCM, Calazans GJ, Saletti Filho HC, França-Junior I. Risco, vulnerabilidade e práticas de prevenção e promoção da saúde. In: Campos GWS, Minayo MCS, Akerman M, Drumond Junior M, Carvalho YM (orgs.). Tratado de saúde coletiva. São Paulo: Hucitec; 2009. p. 375-418.

8. Ayres JRCM, Paiva V, França Jr I. Conceitos e práticas de prevenção: da história natural da doença ao quadro da vulnerabilidade e direitos humanos. In: Paiva V, Ayres JRCM, Buchala CM. In: Vulnerabilidade e Direitos Humanos. Prevenção e Promoção da Saúde, Livro I. Curitiba:Juruá Editora, 2012. p. 71-94.

9. Silva NEK, Sancho LG. O acesso de homens a diagnóstico e tratamento de infecções sexualmente transmissíveis na perspectiva multidimensional e relacional da vulnerabilidade. Interface - Comunic. Saúde Educ. [Internet]; 2013 abr./jun, 17(45):463-71. [citado 11 out 2015]. Disponível em: http://www. scielo.br/pdf/icse/v17n45/18.pdf

10. Alves PCB, Souza IM. Escolha e avaliação de tratamento para problemas de saúde: considerações sobre o itinerário terapêutico. In: Rabelo MC, Alves PCB, Souza IM organizador(es). In: Experiência de doença e narrativa. Rio de Janeiro: Editora Fiocruz, 1999. p. 125-38.

11. Victora C, Knauth D, Hassem MNA. Pesquisa Qualitativa em Saúde. Porto Alegre: Tomo Editorial, 2000.

12. Minayo MCS. O Desafio do Conhecimento. 4a ed. São Paulo-Rio de Janeiro: Hucitec-Abrasco; 1996, p. 211-218.

13. Silva GM, Rasera EF. A desqualificação do SUS na Folha de São Paulo. Construção discursiva de gestores e usuários. Psico PUCRS [Internet]; jan./mar 2013,44(1):82-91. [citado 11 out 2015]. Disponível em: http://revistaseletronicas.pucrs.br/ojs/index.php/revistapsico/article/view/10659/8851

14. Oliveira VCA. A comunicação midiática e o Sistema Único de Saúde. Interface _ Comunic. Saúde, Educ.; 2000, 4(7):71-80. [citado 11 out 2015] Disponível em: http://www.scielo.br/pdf/icse/v4n7/06.pdf

15. Brasil. Instituo Brasileiro de Defesa do Consumidor. O SUS pode ser seu melhor plano de Saúde. 3a ed. São Paulo; 2006. 68 p.

16. Oliveira DC, Sá CP, Santo CCE, Gonçalves TC, Gomes AMT. Memórias e representações sociais dos usuários do SUS acerca dos sistemas públicos de saúde. Rev. Eletr. Enf.; 2011; jan/mar;13(1):30-41. [citado 15 out 2015]Disponível em: https://www.fen.ufg.br/fen revista/v13/n1/pdf/v13n1a04.pdf

17. Brasil. Conselho Nacional de Secretários de Saúde. A saúde na opinião dos brasileiros. Brasilia:Conass; 2003.

18. Halbwachs M. A memória coletiva. São Paulo: Vértice, 1990.

19. Menegon VS. Crise dos serviços de saúde no cotidiano da mídia impressa. Psicol. Soc.; 2008, 20(Edição Especial): 32-40. [citado 11 out 2015]. Disponível em: http://www.scielo.br/pdf/psoc/v20nspe/ v20nspea06.pdf. 
20. Narvai PC. Ocultamento do SUS e guerra simbólica do capital contra a Saúde Pública. Anais do $11^{\circ}$ Congresso Brasileiro de Saúde Coletiva; 2015; Goiânia, Brasil:Abrasco; 2015.

21. Medrado B. Textos em cena: a mídia como prática discursiva. In: Spink MJ (org). Práticas discursivas e produção de sentidos no cotidiano. Aproximações teóricas e metodológicas. São Paulo:Cortez; 1999, p. 243-271.

22. Farias LO. Estratégias individuais de proteção à saúde: um estudo da adesão ao sistema de saúde suplementar. Ciênc. saúde coletiva; 2001, 6(2): 405-16. [citado 11 out 2015]. Disponível em: http:// www.scielo.br/pdf/csc/v6n2/7011.pdf

23. Cegarra J. Fundamentos Teórico Epistemológicos de los Imaginarios Sociales. Ver Cinta de Moebio; 2012, 43: 1-13. [citado 11 out 2015]. Disponível em: http://www.facso.uchile.cl/publicaciones/ moebio/43/cegarra.html

24. Maffesoli M. O imaginário é uma realidade. Revista FAMECOS Midia, Cultura, Tecnologia; 2001, 1(15):7482. [citado 11 out 2015]. Disponível em: http://www.revistas.univerciencia.org/index.php/famecos/ article/view/285/217

25. Baeza MA. Memoria e imaginários sociales. Imagonautas; 2011, 1 (1):76-95. [citado 11 out 2015]. Disponível em: http://dialnet.unirioja.es/ejemplar/372445

26. Castoriadis C. Buenos Aires. São Paulo: Turquest; 2007. 